ORIGINAL ARTICLE

\title{
Medical survey of female boxing in Italy in 2002-2003
}

\author{
M Bianco, A Pannozzo, C Fabbricatore, N Sanna, M Moscetti, V Palmieri, P Zeppilli
}

Br J Sports Med 2005;39:532-536. doi: 10.1136/bjsm.2004.014365

See end of article for authors' affiliations

.....................

Correspondence to: Dr Bianco, Catholic

University, Sports

Medicine, L.gl F. Vito, 1,

Rome 00168, Italy;

massimiliano.bianco@

fastwebnet.it

Accepted

27 September 2004

\begin{abstract}
Background: Female boxing has been permitted in Italy since 2001. According to the latest Italian laws, athletes applying to become boxers have to pass a pre-participation medical examination.

Objective: To collect novel medical information from the pre-participation visits and mandatory precompetition and post-competition examinations for all fights involving Italian female boxers in 20022003.

Methods: A retrospective study on all official female boxing competitions in Italy from January 2002 to October 2003 was conducted. A prospective study on 28 amateur female boxers was also carried out. Results: Retrospective study: data from 664 examinations were collected. Pre-match examinations were negative. After competitions, 19/645 visits showed some injuries, with mild, soft tissue facial lesions, epistaxis, and hand-wrist problems being the most common. Prospective study: no major lesions were found during the study. One fibroadenoma, one ovarian cyst, and one intramural uterine myoma were found. One boxer was referred to a neurologist because of non-specific electroencephalographic (EEG) abnormalities, which persisted six months later. On a re-admission examination, which was needed because of a contest that was stopped because the referee judged that she was receiving blows to the head that were dangerous, one boxer showed non-specific EEG alterations and nystagmus. A cerebral magnetic resonance imaging scan was normal. She was allowed to participate in competitions again when her EEG returned to normal and clinical signs disappeared. Deviation of the nasal septum was quite common (68\%). No major eye injuries were reported.

Conclusion: Probably because of the correct preventive medical approach, female boxing is much safer than expected, and no major lesions (requiring hospital admission) were reported. Any lesions to the breast and reproductive system could not be considered to be boxing related.
\end{abstract}

B oxing is an ancient sport, traditionally only practised by men. However, women have been allowed to compete in Germany since 1995, initiating an athletic movement for a growing number of women to participate in boxing competitions. Over time, competitive boxing has become a reality for women in other countries, leading to international matches and European and World championships, and the International Boxing Federation (AIBA, Association International de Boxe Amateur) is now aiming to include female boxing as an Olympic sport in Beijing 2008. Since April 2001, following the provisions of a new Italian law ${ }^{1}$ integrating the previous laws on amateur ${ }^{2}$ and professional athletes and boxers, ${ }^{3}$ Italian women have been allowed to participate in competitive boxing, at both the amateur and professional level. As provided by the law, the medical section of the Italian Boxing Federation (Federazione Pugilistica Italiana, FPI) has carried out widespread monitoring of the medical risks of female boxers, collecting data on competitive matches taking place in Italy over three years, as well as competitions abroad involving Italian athletes. Moreover, a prospective study was conducted to assess medical problems that may be correlated with boxing.

\section{MATERIALS AND METHODS}

We considered all female boxing competitions that took place in Italy from January 2002 to October 2003 (22 months). Our research was designed in two sections.

- A retrospective study of all competitions involving female boxers (amateur and professional), including foreign boxers fighting in Italy and Italian boxers fighting abroad (Amateur World Championship in Turkey, 2002 and Amateur European Championship in Hungary, 2003).

- A prospective study of amateur female boxers affiliated to the FPI in Lazio region, which was chosen as it is the most active regional boxing committee in Italy. In this section, we mainly considered lesions involving the breast, reproductive and nervous systems, the eye, ear, nose, and throat.

Besides the pre-participation examination required for affiliation to the FPI, ${ }^{2}{ }^{3}$ all athletes had to comply with the examinations specified by the new law. ${ }^{1}$

(1) Before affiliation:

- ascertainment of sex on starting competitive activity;

- breast examination and mammary ultrasound (once a year);

- pelvic ultrasound (once a year);

- mammary radiograph when appropriate.

(2) Before each competition:

- medical examination (carried out by ringside doctor at weigh in) especially of the breast, abdomen, and pelvis. Boxers also have to provide a negative pregnancy test (performed less than five days before) and, as provided by Art 3 of the new law, ${ }^{1}$ to sign a declaration saying that they did not suffer from vaginal bleeding (other than normal menses), pelvic tumoral masses, urinary symptoms, recent surgery and/or trauma, or significant menstrual changes.

(3) After each competition:

- medical examination (carried out by ringside doctor immediately after the fight) especially of the breast, abdomen, and pelvis. 
Table 1 shows the abbreviations used to indicate a boxing verdict when matches are stopped before the time limit.

\section{RESULTS}

\section{Technical information}

Amateur female boxers compete in bouts of three rounds of two minutes each, with one minute of rest between rounds. Fights for professional female boxers consist of from four up to 10 rounds of two minutes each, with one minute of rest between rounds. All boxers wear 10 ounce ( $284 \mathrm{~g}$ ) gloves and a mouthguard during contests. Following Italian law, both amateur and professional boxers wear breast and genitalia protectors and headguard during competitions.

In 2002, 102 athletes were affiliated to the FPI, 98 (96\%) amateur and four (4\%) professional, fighting a total of 174 matches (161 amateur and 13 professional). Twenty eight amateur matches (17\%) were stopped before the time limit (verdicts RSC in five, RSCH in seven, RSCI in nine, RSCO in five, disqualification in one, and voluntary abandon in one). Three professional matches $(23 \%)$ were stopped before the time limit: KOT in two and voluntary abandon in one. During this time, one Italian amateur boxer succeeded in retaining her title, and another won a silver medal. Three professional athletes became European Champions.

In 2003, the number of women affiliated to the FPI had grown to 150,146 amateur (97\%) and four professional (3\%), fighting a total of 184 matches (175 amateur and nine professional). Nineteen amateur matches (11\%) were stopped before the time limit: RSC in five, RSCH in four, RSCI in two, RSCO in three, WO in one, disqualification in two, and abandon in one. Three professional matches were stopped before the time limit (33\%): KOT in two and voluntary abandon in one. Over this period, the best results were two gold medals and two bronze medals at the Amateur European Championship in Hungary, and the title of European Professional Champion, achieved by three boxers.

\section{Retrospective study}

From January 2002 to October 2003, we collected data on 664 medical examinations in boxers (mean (SD) age 23.78 (4.81) years) fighting official matches. These data came from 321 bouts that took place in Italy ( 642 boxers) and 22 abroad (22 boxers, examined by the Italian medical official accompanying the team). All pre-match declarations and pregnancy tests were unremarkable. In particular, no boxers

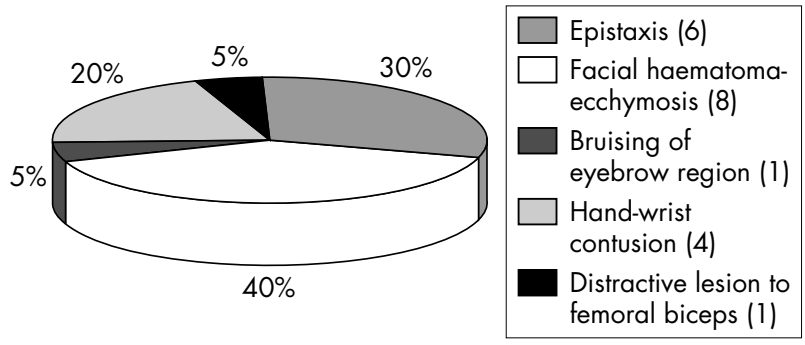

Figure 1 Medical problems after 343 competitions (321 in Italy-642 boxers examined; 22 abroad -22 boxers examined): 19 of 664 boxers $(2.9 \%)$ suffered 20 injuries.

reported vaginal bleeding other than that normally related to menses, tumoral pelvic masses, or urinary symptoms. Only one athlete showed mild hyperaemia of the right eye.

After the fights, 645 boxers $(97.1 \%)$ had no noteworthy lesions. In the rest, we observed (fig 1): mild contusions to the soft tissue of the face, blood suffusion or ecchymosis to the zygomatic region, eyebrow, and eyelid $(n=8)$; epistaxis ( $\mathrm{n}=6$, one of whom also had inferior right eyelid ecchymosis); contusions to the hand and wrist $(\mathrm{n}=4)$; one small bruise to the right eyebrow region not requiring surgical care. One boxer experienced a mild injury due to indirect trauma to her right femoral biceps. No lesions to the mammary area were found, including haematoma, ecchymosis, and cysts, nor were there any reports of abdominal or pelvic symptoms and conditions possibly connected to fighting. During competition and in the days following, no boxers reported acute symptoms or severe conditions requiring hospital admission.

\section{Prospective study in Lazio region}

From January 2002 to October 2003, 28 female amateur athletes (mean (SD) age 24.18 (3.70) years) were affiliated to the FPI as boxers in the Lazio region, thus complying with the medical examinations required by current Italian laws. One other athlete applied for affiliation, and she is not included in our statistics because she had breast surgery in 2001 for aesthetic purposes, with positioning of bilateral prostheses: for the same reason, she was not admitted to competitive boxing (as required by Art 4 of the new Italian law). ${ }^{1}$ Over our study period of about 22 months (mean (SD)

Table 1 Possible verdicts when matches are stopped before the time limit

Amateur boxing

- Referee stop contest (RSC)

- Referee stop contest head (RSCH)

- Referee stop contest outclassed (RSCO)

- Referee stop contest injury (RSCI)

- Knock out (KO)

- Abandon

- Disqualification

- No contest (NC)

- Walk over (WO)

Professional boxing

- Technical knock out (KOT)

- Technical knock out cut (KOTC)

- Knock out (KO)

- Abandon

- Disqualification

- No contest (NC)
Referee stops the contest when one opponent is unable to carry on or is clearly inferior

Referee stops the contest because of blows to the head which are judged to be dangerous within the purposes of the competition

Referee stops the contest because of a difference in the score greater than 15 points (score machines)

Referee stops the contests because of medical intervention

One opponent is unable to resume fighting after being counted out Voluntary abandonment of the contest by one opponent or her/his team

Unfair, non-sporting behaviour

The fight is suspended without declaration of a winner

One opponent does not show up

Referee stops the contest when one opponent is unable to carry on or is clearly inferior

Referee stops the contest because of a significant bruise or injury

One opponent is unable to resume fighting after being counted out

Voluntary abandonment of the contest by one opponent or her/his team

Unfair, non-sporting behaviour

Fight is suspended without declaration of a winner 
follow up 10.1 (3.2) months), eight of the 28 boxers took part in official competitions (between one and 14 fights each), a total of 40 fights $(4.4$ (4.5) per boxer). Three (7.5\%) were stopped before the time limit, due to RSCH. Of the 28 boxers included, 10 had to pass more than one medical check up over 22 months, either the annual examination for the purposes of affiliation ( $\mathrm{n}=7$ ) or for re-admission after fights lost and stopped before the time limit.

\section{Mammary area}

At their first visit, examination and ultrasound were both negative in all 28 athletes included. One boxer, aged 28, who had more than one examination during the study period for the yearly affiliation was found to have a round shaped, hypoechogenic mass $(11 \times 5 \mathrm{~mm}$ in size $)$, which was diagnosed as a fibroadenoma. This boxer, although training regularly, did not take part in competitions during the year. The medical commission of the FPI, after consulting a specialist, decided to grant eligibility to box, although they made it mandatory for the boxer to have a check up every six months. Over the study period, no boxers showed evidence of haematoma, cysts, or phlogistic conditions of the breast.

\section{Reproductive system}

At their first visit, all the boxers reported having regular menses with respect to rhythm, quantity, and duration, with the first menses at a mean (SD) age of 12.1 (1.0) years. None were taking oral contraceptives, and none had ever been pregnant. Examination of the reproductive system produced negative results in all cases, and pelvic ultrasound examination found in one case $(3.5 \%)$ a left ovarian cyst (maximum diameter $22 \mathrm{~mm}$ ), judged by specialists to be no contraindication to competitive boxing.

In the boxers who had repeat examinations during our follow up, pelvic ultrasound confirmed the left ovarian mass, the size of which was unchanged. This athlete had taken part in one fight, which she had lost on points. At re-affiliation, one boxer reported polymenorrhoea, and pelvic ultrasound showed an intramural myoma (maximum diameter $14 \mathrm{~mm}$ ), which had not been found one year previously. She had taken part in two fights (one won and one lost, both on points). According to specialists, the condition did not contraindicate competitive boxing, but was itself a reason for a check up every six months.

\section{Nervous system}

At their first visit, neurological examination was unremarkable in all the boxers, but the EEG showed "non-specific anomalies" in one case. This boxer was suspended from boxing, and she was asked to have a repeat EEG after six months. As the anomalies were confirmed, she was referred to a neurologist for further tests, which are now being performed.

At her re-admission visit due to a match lost by $\mathrm{RSCH}$, one boxer showed "non-specific anomalies" on the EEG, first degree nystagmus when looking leftwards, and right side deviation while marching with closed eyes. Cranial-encephalic magnetic resonance was therefore requested. The skull and encephalic and cerebellar areas were shown to be completely normal. In the meantime, the neurological symptoms subsided, and she was therefore re-admitted to competitive boxing.

\section{The eye}

At their first examination, nine boxers out of the 28 (32\%) had myopia, of moderate to high degree in five cases. They were admitted to competition but were obliged to wear soft contact lenses during both training and matches.
In one athlete with high degree myopia (1/10 uncorrected vision in both eyes), examination of the fundus oculi showed a mildly dystrophic retina which was judged not to be important with respect to competitive boxing. Another athlete with high degree myopia ( $1 / 10$ uncorrected vision in both eyes) showed signs of successful therapeutic laser treatment for peripheral retinal degeneration and microlesions. This boxer was also judged to be eligible to box. Lastly, a mild inferior retinal dystrophy was found in a young woman with normal vision, but it was the ophthalmologists' opinion that this did not contraindicate competitive boxing.

Over our study period, one boxer with high degree myopia had surgical treatment (photo-refractive keratotomy) with good outcome and nearly full recovery of sight. Examination of the fundus oculi confirmed the mild inferior retinal dystrophy already reported. This boxer was having the yearly examination for affiliation to the FPI, after six fights in the previous year (four won and two lost, all on points).

Periocular soft tissue, eye pressure, and lenticular apparatus were found to be normal in all cases and on all occasions.

\section{Ear, nose, and throat}

At the first examination, one boxer showed mild tympanic bilateral retraction and mild transmissive hypacusia. The latter was also found in another boxer. These anomalies were judged not to contraindicate competitive boxing; however, the two athletes did not take part in competitions, and did not apply for affiliation the following year.

Of 28 athletes examined, two showed signs of past fracture of the nasal pyramid at their first examination, and the nasal septum was found to be slightly deviated in 19 cases (68\%). At her second examination for re-affiliation, one boxer whose nose was reported to be normal at her first examination, showed signs of nasal bone fracture and mild nasal septum deviation, which were attributed to the outcome of a match lost by RSCH. This boxer participated in nine fights in one year, with a score of four won, three lost, and two drawn.

\section{DISCUSSION}

Data collected in the first three years of female boxing in Italy show growing interest in the sport, as suggested by the increase in the number of women affiliated to the FPI, from 26 in 2001 to 150 in 2003. Italian female boxers have reached satisfactory levels in international competitions, both amateur and professional, allowing us to consider them a valid study population in the international setting.

\section{Retrospective study}

Data on the total number of fights in Italy over nearly two years have shown a prevalence of medical conditions related to fighting of $2.86 \%$ and an incidence of $1.56 \%$ a year, similar to that found in male boxing. ${ }^{4}$ Even though $11-17 \%$ of fights ended before the time limit, only 19/664 boxers showed clinical signs of traumatic injury at the post-competition examination. This may be due to more prudent refereeing and cautious rules adopted for female boxing.

The most commonly reported lesions were small ecchymosis/haematoma involving the face, epistaxis, and one case of laceration and contused bruising of the eyebrow area, not requiring surgical care. No severe injuries were observed, nor did we find any conditions involving the reproductive system and breast clearly caused by boxing. Furthermore, since its official inception, female boxing has not caused any acute severe conditions requiring immediate hospital admission, as a result of training or fighting.

\section{Prospective study}

The prospective study over the very first two years of Italian female boxing seems to rule out any problems to the 


\section{What is already known on this topic}

Women have been allowed to compete in boxing for only a few years. Very little is known about the injury rate of female boxing and any health problems related to the practice of this sport in women.

reproductive system or breast as a clear consequence of boxing. One of the 28 athletes (4\%) taking part in our 22 month follow up had a left ovarian cyst, which appeared to be unchanged in size after one year of boxing. Even though the study population is not large, this finding is in line with data on the general population, showing a prevalence of benign ovarian cysts of $4.8-6.6 \%$ in women aged $25-40 .{ }^{67}$ No direct relation is thought to exist between pelvic trauma and ovarian cysts, and there are no scientific data to support a link between abdominal-pelvic trauma and the formation of intramural myoma of the uterus. For this reason, our single case of myoma is probably just a casual finding, although it seems reasonable to discourage boxing, as well as any other traumatic sport, in athletes with large masses in their reproductive system.

As far as the breast is concerned, fibroadenoma is the most common benign lesion, with the highest incidence in the third decade. There are no scientific data to support a relation between benign lesions and trauma to the mammary area. We did not observe any haematoma, cysts, and/or phlogistic conditions involving the mammary gland in the athletes examined

The findings on the nervous system, the eye, ear, nose, and throat did not suggest any significant differences based on sex, as far as boxing injuries are concerned. However, with the aim of better defining the inherent traumatic risk of boxers, these systems were closely analysed. In our study population, one boxer showed non-specific EEG anomalies at her first examination, which remained unchanged after six months of withdrawal from boxing training and competitions. She was therefore suspended and referred to a specialist. Another boxer, after a fight lost by RSCH, showed first degree nystagmus and rightwards deviation while marching with closed eyes, together with the onset of nonspecific EEG anomalies. A cranial-encephalic magnetic resonance imaging scan was therefore carried out, with normal results. As neurological symptoms had subsided, the boxer was re-admitted to competition, after the regulation 30 day suspension period indicated by current law. ${ }^{2}$

The rate of myopia was $32 \%$, similar to that observed in the general population. ${ }^{-11}$ One boxer with high degree myopia also showed mild peripheral retinal dystrophy on examination of the fundus oculi, a condition known to be commonly associated with refractory anomalies. ${ }^{12}$ This condition, according to our consultant specialists, does not increase the risk of traumatic retinal detachment. Moreover, such a risk is not judged to be increased by mild retinal dystrophy with normal vision or by photo-refractive keratotomy, which one athlete had for the treatment of more severe retinal lesions (degeneration and microlesions), which she probably had in association with high degree myopia. ${ }^{9}{ }^{17}$ Concerning pathology of the ear, nose, and throat, the prevalence of mild bilateral hypacusia $(7 \%)$ in our athletes is similar to that reported in the general population, ${ }^{18}{ }^{19}$ although trauma to the ear area may indirectly perforate the tympanic membrane which, when underestimated, can cause transmissive hypacusia even more severe than actually found.

Fracture of nasal bones is the most common nasal lesion in boxing, ${ }^{20}{ }^{21}$ as in other sports in which impact is an integral part of the sport. ${ }^{22-24}$ Signs of fracture of the nasal pyramid
What this study adds

This retrospective and prospective study shows female boxing to be much safer than expected. No injuries, particularly to the breast and reproductive system, seem to be related to boxing activity.

were already found in two boxers at their first examination $(7 \%)$, and a third case was reported at re-admission. Nasal septum deviation was found in 19 athletes (68\%) at first examination, a higher prevalence than in the age matched general population $(40 \%){ }^{25} 26$

\section{CONCLUSIONS}

In our medical survey of female boxing in Italy, we have recorded no acute or severe events. Moreover, we have not observed any conditions of the reproductive system or the breast that can be attributed to boxing, either amateur or professional. Furthermore, anomalies of the nervous system, the eye, ear, nose, and throat seem to have the same prevalence as in the age matched general population, or in male boxing. For these reasons, we believe that female boxing, as well as male boxing, receives satisfactory medical provision in Italy. This is due, to some extent, to the close attention of the National Health Office $^{1-3}$ and the tight controls operated by the medical section of the FPI

The general picture of Italian female boxing that emerges is that it entails much the same risks as any other female sports in which opposing players share an arena and impacts occur, either intentionally or as the result of the competition (soccer, hockey, etc). Therefore female boxing should now be able to rid itself of the label of "experimental sport" in Italy and find its way to becoming an official sport.

\section{Authors' affiliations}

M Bianco, A Pannozzo, C Fabbricatore, N Sanna, V Palmieri, P Zeppilli, Catholic University of Sacred Heart, Rome, Italy

M Moscetti, Italian Boxing Federation, Rome, Italy

Competing interests: none declared

Ethics approval: This study was approved by the ethics committees of the relevant institutions.

\section{REFERENCES}

1 Decreto Ministeriale 4 aprile 2001. Gazzetta Ufficiale della Repubblica Italiana-Serie Generale del 17 aprile, 2001;89.

2 Decreto Ministeriale 18 febbraio 1982. Gazzetta Ufficiale della Repubblica Italiana-Serie Generale del 5 marzo, 1982;62.

3 Decreto Ministeriale 13 marzo 1995. Gazzetta Ufficiale della Repubblica Italiana-Serie Generale del 28 aprile, 1995;98.

4 Rondoni F. L'indice di pericolosità e la frequenza d'infortunio. In: Rondoni F, ed. Manuale di medicina dello sport applicata al pugilato. Assisi (PG): Tipografia Metastasio, 1996:161-3.

5 Estwanik JJ. Injuries to the extremities, trunk, and head. In: Cantu RC, ed Boxing and medicine. Champaign, IL: Human Kinetics, 1995:79-87.

6 De Rosa G, Catalano D, Dell'Isola A, et al. [The role of transvaginal ultrasonography in the screening of ovarian tumors]. Minerva Ginecol 1997;49:243-9.

7 Borgfeldt C, Andolf E. Transvaginal sonographic ovarian findings in a random sample of women 25-40 years old. Ultrasound Obstet Gynecol 1999:13:345-50.

8 Robbins SL, Kumar V. Apparato genitale femminile e mammella. In: Robbins SL, Kumar V, eds. Anatomia patologica. Rome: EMSI, 1993:769-70.

9 Mavracanas TA, Mandalos A, Peios D, et al. Prevalence of myopia in a sample of Greek students. Acta Ophthalmol Scand 2000;78:656-9.

10 Fledelius HC. Myopia profile in Copenhagen medical students 1996-98. Refractive stability over a century is suggested. Acta Ophthalmol Scand 2000;78:501-5.

11 Kinge B, Midelfart A. Refractive changes among Norwegian university students: a three-year longitudinal study. Acta Ophthalmol Scand 1999;77:302-5.

12 Neacsu A, Stefan C. [Myopic peripheral retinal degenerations]. Oftalmologia 2001;51:4-7. 
13 Lewis $\mathrm{H}$. Peripheral retinal degenerations and the risk of retinal detachment. Am J Ophthalmol 2003;136:155-60.

14 Dolan BJ. Traumatic retinal detachment. Optom Clin 1993;3:67-80.

15 Johnston PB. Traumatic retinal detachment. Br J Ophthalmol 1991;75:18-21.

16 Williams DF, Mieler WF, Williams GA. Posterior segment manifestations of ocular trauma. Retina 1990;10(suppl 1):S35-44.

17 Grossniklaus HE, Green WR. Pathologic findings in pathologic myopia. Retina 1992;12:127-33.

18 Johansson MS, Arlinger SD. Prevalence of hearing impairment in a population in Sweden. Int J Audiol 2003:42:18-28.

19 Wilson DH, Walsh PG, Sanchez L, et al. The epidemiology of hearing impairment in an Australian adult population. Int J Epidemiol 1999;28:247-52.

20 Rondoni F. I traumatismi del naso. In: Rondoni F, ed. Manuale di medicina dello sport applicata al pugilato. Assisi (Perugia): Tipografia Metastasio, 1996:196-201.
21 Lavorgna G, Russo A, Ambrosio A, Alterio F, Dell'Aquila A. [Injuries of the nasal bone in boxing]. Minerva Chir 1995;50:895-9.

22 Cerulli G, Carboni A, Mercurio A, et al. Soccer-related craniomaxillofacial injuries. J Craniofac Surg 2002;13:627-30.

23 Maladiere E, Bado F, Meningaud JP, et al. Aetiology and incidence of facial fractures sustained during sports: a prospective study of 140 patients. Int $J$ Oral Maxillofac Surg 2001;30:291-5.

24 Tanaka N, Hayashi S, Amagasa T, et al. Maxillofacial fractures sustained during sports. J Oral Maxillofac Surg 1996;54:715-19, discussion 719-20.

25 Gray LP. Deviated nasal septum. Incidence and etiology. Ann Otol Rhinol Laryngol Suppl 1978;87(suppl 50):3-20.

26 Subaric M, Mladina R. Nasal septum deformities in children and adolescents: a cross sectional study of children from Zagreb, Croatia. Int J Pediatr Otorhinolaryngol 2002;63:41-8.

\section{bmjupdates+}

bmjupdates+ is a unique and free alerting service, designed to keep you up to date with the medical literature that is truly important to your practice.

bmjupdates+ will alert you to important new research and will provide you with the best new evidence concerning important advances in health care, tailored to your medical interests and time demands.

\section{Where does the information come from?}

bmiupdates+ applies an expert critical appraisal filter to over 100 top medical journals A panel of over 2000 physicians find the few 'must read' studies for each area of clinical interest

Sign up to receive your tailored email alerts, searching access and more...

www.bmjupdates.com 